\title{
RETROSPECTIVE STUDY OF DEEP NECK SPACE INFECTIONS
}

\author{
Madhusudhen Reddy Geedikanti ${ }^{1}$, Parusharam Nagula², Rajendra Prasad Janga ${ }^{3}$, Kaushik Kumar 4 \\ ${ }^{1}$ Associate Professor, Department of Otorhinolaryngology, Kakatiya Medical College/ MGM Hospital, Warangal, Telangana. \\ ${ }^{2}$ Associate Professor, Department of Otorhinolaryngology, Kakatiya Medical College/ MGM Hospital, Warangal, Telangana. \\ 3 Senior Resident, Department of Otorhinolaryngology, Kakatiya Medical College/ MGM Hospital, Warangal, Telangana. \\ ${ }^{4}$ House Surgeon, Department of Otorhinolaryngology, Kakatiya Medical College/ MGM Hospital, Warangal, Telangana.
}

\section{BACKGROUND}

ABSTRACT

Deep neck space infections are bacterial infections of the fascial planes and potential spaces of the head and neck. DNSIs are seen across all age groups depending on the primary cause. The primary causes of DNSI include odontogenic infections, tonsillar and peritonsillar infections, malignancies and foreign body ingestion. The advent of antibiotics has reduced the incidence of DNSI, but DNSI poses a challenge due its propensity to cause life-threatening complications and decompensates a well looking patient very rapidly. Treatment of DNSI includes prompt surgical drainage and administering appropriate antibiotics with or without airway support based on the alert signs like respiratory distress, stridor and neck stiffness.

This study aims to investigate and understand the patterns of DNSI across all ages and gender with its presentation, signs, sites involved, bacteriology, management and complications.

\section{MATERIALS AND METHODS}

This is a retrospective descriptive study of 94 patients with DNSI admitted in the ENT Department from February 2015 to October 2016. Patients of all age groups and gender were included. All clinical parameters were included in the study including comorbidities, clinical presentation, site, causative organism, complications, treatment and management across all age groups with mean age being 45 years.

\section{RESULTS}

In our report, there were 55 male patients and 25 female patients. Diabetes was found as a comorbid condition in 19 cases $(23.7 \%)$. The mean age was 45 years. Our study found out that the most frequent causes of DNSI were odontogenic conditions (27.5\%). Neck and/ or facial oedema in all patients with local pain in 79 patients $(98.75 \%)$ were the most common symptoms of DNSI. The most commonly isolated bacterium was Staphylococcus aureus in 30 patients (37.5\%) followed by Group G Streptococcus in 20 patients (25\%). Among complications, the presence of septic shock and mediastinitis were statistically significant variables associated with the demise group. Surgery was done in 78 patients (97.5\%), of which 55 patients underwent neck drainage only.

\section{CONCLUSION}

DNSI carries significant risks of life-threatening complications including death. This necessitates the need for accurate diagnosis and prompt management to provide a cure without complications, and to always promptly identify alert signs such as stridor and neck stiffness. Management of DNSI traditionally is based on antibiotic treatment with prompt surgical drainage of abscess. The study brings to light the importance of prompt diagnosis and treatment of DNSI and the importance of oral hygiene, especially in developing countries.

\section{KEYWORDS}

Deep Neck Space Infections, Surgical Drainage, Dental Infections, Tonsillar and Salivary Gland Infections.

HOW TO CITE THIS ARTICLE: Geedikanti MR, Nagula P, Janga RP, et al. Retrospective study of deep neck space infections. J. Evolution Med. Dent. Sci. 2017;6(91):6528-6532, DOI: 10.14260/jemds/2017/1416

\section{BACKGROUND}

Deep neck space infections (DNSI) are bacterial infections in the fascial planes and potential spaces of the head and neck, originating from the mucosal surface of the upper aerodigestive tract. ${ }^{1,2}$ These spaces form a complex structure in the neck and are formed by fascial planes. There are around 11 deep spaces.

'Financial or Other Competing Interest': None.

Submission 07-10-2017, Peer Review 10-11-2017,

Acceptance 17-11-2017, Published 27-11-2017.

Corresponding Author:

Dr. Parusharam Nagula,

H. No. 2-6-1422/1,

Srinivasa Colony, Bhavani Nagar,

Hanamakonda, Warangal-560001,

Telangana, India.

E-mail: parashuramnagula@gmail.com

DOI: $10.14260 /$ jemds $/ 2017 / 1416$
DNSI primarily arise from a septic focus in the tonsils, dental caries, pharynx and upper aerodigestive tract. The infections originating from the teeth and adjacent structures called as odontogenic infections are now the most common cause of DNSI in developing countries. ${ }^{3}$ This brings to light the importance of dental hygiene and educating the population about the same. Prior to the advent of antibiotics, tonsillar and peritonsillar infections were the source of infection in $70 \%$ of the cases of DNSI. ${ }^{4}$ DNSI are usually polymicrobial in nature. Staphylococcus, Streptococcus, Peptostreptococcus and anaerobes are most commonly cultured organisms from DNSI.5,6 The most common comorbid condition associated with DNSI is diabetes mellitus. DNSI presents clinically with neck pain, trismus, fever, odynophagia, dysphagia, malaise, fatigue, dysphonia and dyspnoea. ${ }^{7}$ These infections are significantly life-threatening in nature with a variety of associated complications such as 
airway obstruction, jugular vein thrombophlebitis (Lemierre's syndrome), mediastinitis, pleural empyema, cavernous sinus thrombosis, pericarditis, sepsis, disseminated intravascular coagulation, respiratory distress, pleuropulmonary suppuration and haematogenous dissemination to distant organs. ${ }^{8}$ Hence, the surgeon should not be fooled as a relatively well looking patient can decompensate very rapidly.

The diagnosis of DNSI is usually made based on clinical presentation, radiological findings and history of the patient. Treatment of DNSI includes conservative antibiotic treatment, airway management and surgical intervention. ${ }^{9}$ Management involved prompt surgical drainage of the abscess followed by appropriate antibiotics based on culture and sensitivity. However, not all patients require surgical intervention. This study aims to share our experience in terms of incidence, clinical features, bacteriology, common sites, management, complications and outcomes.

\section{Aims and Objectives}

1. To study the incidence and clinical features of deep neck space infections.

2. To evaluate the aetiology and possible causative organism in deep neck space infections.

3. To study the management of deep neck space infections and complications encountered.

\section{MATERIALS AND METHODS}

This is a retrospective descriptive study of 94 patients who were admitted and treated for DNSI in the Department of Otorhinolaryngology from February 2015 to October 2016. A total of 80 patients met our inclusion criteria. Patients admitted due to infection related to inhalation injuries or due to malignancies were excluded. The study included all the parameters including age, gender, comorbidities and subsequently the symptoms, culture growth, bacteriology, common presentations, type of intervention required, airway obstruction, factors affecting patients who did not survive, complications and outcomes of the patients were identified. For antibiotic treatment, all the patients received amoxicillin, clavulanate and metronidazole, which was later modified based on culture and sensitivity.

\section{RESULTS}

There were 55 male and 25 female patients. Fourteen patients had arterial hypertension (17.5\%), 19 were diabetic (23.75\%), 4 had lung diseases (5\%) and 3 were HIV-positive (3.75\%). The mean age was 45 years. Smoking was reported by 23 patients $(28.75 \%)$ and use of alcoholic beverages was reported by 13 patients $(16.25 \%)$.

\begin{tabular}{|c|c|c|}
\hline Gender & Number & Percentage \\
\hline Male & 55 & 69 \\
\hline Female & 25 & 31 \\
\hline \multicolumn{3}{|c|}{ Table 1. Sex Distribution } \\
\hline
\end{tabular}

Odontogenic conditions were the most frequent causes of DNSI (27.5\%) followed by tonsillitis diseases (22.5\%), skin infection $(8.75 \%)$ and parotid infection $(6.25 \%)$. The cause was unclear in 20 patients $(25 \%)$. Other causes $(10 \%)$ were ganglionar tuberculosis with abscess $(\mathrm{n}=3)$, local trauma $(n=2)$, complicated otitis media $(n=1)$, infected thyroglossal cyst $(n=1)$ and deep infection related to a central venous catheter $(n=1)$.

\begin{tabular}{|c|c|c|}
\hline Causes & Number & Percentage \\
\hline Odontogenic & 22 & 27.5 \\
\hline Tonsillar & 18 & 22.5 \\
\hline Skin infection & 7 & 8.7 \\
\hline Parotid & 5 & 6.2 \\
\hline Tuberculosis & 3 & 3.7 \\
\hline Trauma & 2 & 2.5 \\
\hline Complicated otitis media & 1 & 1.2 \\
\hline Infected thyroglossal cyst & 1 & 1.2 \\
\hline Infected central line catheter & 1 & 1.2 \\
\hline Unknown & 20 & 25 \\
\hline \multicolumn{3}{|c|}{ Table 2. Aetiology of Neck Infections } \\
\hline
\end{tabular}

The symptoms of DNSI were neck and/ or facial oedema in all patients, local pain in 79 patients (98.75\%), fever in 68 patients (85\%), odynophagia in 19 patients $(23.75 \%)$, dysphagia in 9 patients (11.25\%), difficulty breathing in 8 patients $(10 \%)$ and dental pain in 3 patients $(3.75 \%)$. The physical examination demonstrated oedema of the neck in all patients. There was dental infection in 22 patients $(27.5 \%)$, peritonsillar infection in 18 patients (22.5\%), trismus in 27 patients $(33.75 \%)$, tachycardia in 20 patients $(25 \%)$ and toxaemia in 19 patients $(23.75 \%)$. Septic shock was seen in 7 patients $(8.75 \%)$. A pleural effusion was found in 6 patients (7.5\%). Signs of skin necrosis were present in 1 patient. There was hyperaemia in furculum and thorax in 11 patients (13.75\%).

\begin{tabular}{|c|c|c|}
\hline Symptoms & Number & Percentage \\
\hline Oedema & 80 & 100 \\
\hline Fever & 68 & 85 \\
\hline Trismus & 27 & 33.75 \\
\hline Dental pain & 3 & 3.75 \\
\hline Tachycardia & 20 & 25 \\
\hline Toxaemia & 19 & 23.75 \\
\hline $\begin{array}{l}\text { Peritonsillar } \\
\text { infection }\end{array}$ & 18 & 22.5 \\
\hline Shock & 7 & 8.75 \\
\hline \multicolumn{3}{|c|}{ Table 3. Incidence of Various Symptoms } \\
\hline
\end{tabular}

Airways that were difficult to access occurred in 7 patients $(8.75 \%) ; 3$ underwent cricothyroidotomy upon admission and 5 were intubated but considered difficult cases by anaesthesiologists. There were no retrograde intubation cases.

Surgery was done in 78 patients, of which 55 patients underwent neck drainage. Drainage of neck with debridement of tissues was done in 7 patients; drainage if the neck and tracheostomy was done in 6 patients; drainage of the neck and mastoidectomy was done in 1 patient. All of the patients that were drained received intravenous antibiotics. Conservative therapy with intravenous antibiotics and antiinflammatory drugs was used in 11 patients. 


\begin{tabular}{|c|c|c|}
\hline Treatment & Number & Percentage \\
\hline Cervical drainage & 55 & 68.75 \\
\hline Cervical drainage and debridement & 7 & 8.75 \\
\hline Cervical drainage and tracheostomy & 6 & 7.50 \\
\hline $\begin{array}{l}\text { Cervical drainage and } \\
\text { mastoidectomy }\end{array}$ & 1 & 1.25 \\
\hline Conservative & 11 & 13.75 \\
\hline \multicolumn{3}{|c|}{ Table 4. Various Modalities of Management } \\
\hline
\end{tabular}

Infection was located in the following neck spaces: the submandibular space in 36 patients, the parapharyngeal and submandibular spaces in 13 patients, the parapharyngeal space only in 15 patients, the posterior region of the neck in 5 patients, the parotid space in 2 patients, the retropharyngeal space in 3 patients and the mastoid region and submandibular space in 1 patient. The infectious bacteria were 65 positive cultures. The most commonly isolated bacteria was Staphylococcus aureus in 30 patients $(37.5 \%)$ followed by Group G Streptococci in 20 patients (25\%). Thirteen cultured had no bacterial growth after 48 hours incubation. Other bacteria are shown below table.

\begin{tabular}{|c|c|c|}
\hline Cultured Bacteria & Number & Percentage \\
\hline Staphylococcus aureus & 30 & 37.50 \\
\hline Staphylococcus Group G & 20 & 25.00 \\
\hline Streptococcus viridans & 10 & 12.50 \\
\hline Streptococcus pyogenes & 02 & 2.50 \\
\hline Bacteroides & 03 & 3.75 \\
\hline Pseudomonas & 02 & 2.50 \\
\hline Negative culture & 13 & 16.25 \\
\hline \multicolumn{3}{|c|}{ Table 5. Incidence of Various Bacteria } \\
\hline
\end{tabular}

Among complications, the presence of septic shock and mediastinitis were statistically significant variables associated with the demise group.

\begin{tabular}{|c|c|c|}
\hline Complications & Number & Percentage \\
\hline Septic shock & 7 & 8.75 \\
\hline Pleural effusion & 6 & 7.50 \\
\hline Mediastinitis & 5 & 6.25 \\
\hline $\begin{array}{c}\text { Upper airway } \\
\text { obstruction }\end{array}$ & 3 & 3.75 \\
\hline Necrosis of skin & 1 & 1.25 \\
\hline \multicolumn{2}{|c|}{ Table 6. Various Types of Complications } \\
\hline
\end{tabular}

The mortality rate was $11.25 \%(n=9)$. Of the 9 deaths, 5 were male and 4 were female. Four were diabetics, 1 had hypertension and 1 had cancer of the colon that was being treated by chemotherapy. The most common primary cause in these cases was tonsillar disease $(n=4)$ followed by dental conditions $(n=3)$; the origin was not defined in 2 cases. The sites of infection in these cases were the parapharyngeal space in 8 patients and the retropharyngeal space in 1 patient. The upper mediastinitis was involved in 3 of these cases and the whole of mediastinitis was involved in 2 of these cases. In the latter, these were unilateral pleural effusions. The patient that had involvement of the retropharyngeal space also had a large bilateral pleural effusion. Three patients were reoperated, requiring a second drainage of the neck. Seven patients died due to septicaemia, 1 due to an acute myocardial infarction.
The Mann-Whitney method was used for the statistical analysis to establish possible predisposing factors for a poor prognosis of this infection. The group that progressed to death (demise group) was compared with the group with favourable outcome (non-demise group).

Clinical presentation, infection site, surgical findings and complication factors as described above were analysed, taking into account a statistical significance if $\mathrm{p}<0.05$.

In the clinical presentation, the presence of tachycardia (heart rate over 80 beats per minute), signs of toxaemia, signs of tissue necrosis and respiratory failure were statistically significant factors in the demise group.

\begin{tabular}{|c|c|c|c|}
\hline $\begin{array}{c}\text { Potential } \\
\text { Factors }\end{array}$ & $\begin{array}{c}\text { Non-Demise } \\
\text { Group }\end{array}$ & $\begin{array}{c}\text { Demise } \\
\text { Group }\end{array}$ & P value \\
\hline Tachycardia & 19.7 & 66.7 & 0.002 \\
\hline Toxaemia & 19.7 & 55.6 & 0.018 \\
\hline Tissue necrosis & 0 & 11.1 & 0.005 \\
\hline Respiratory failure & 4.2 & 55.6 & Less 0.001 \\
\hline
\end{tabular}

Table 7. Analysis of Potential Factors of Poor Prognosis of DNSI in the Clinical Presentation

Among the complications, the presence of septic shock and mediastinitis were statistically significant variables associated with the demise group.

\begin{tabular}{|c|c|c|c|}
\hline Complications & $\begin{array}{c}\text { Non-Demise } \\
\text { Group }\end{array}$ & $\begin{array}{c}\text { Demise } \\
\text { Group }\end{array}$ & P value \\
\hline Septic shock & 2.8 & 55.6 & Less 0.001 \\
\hline Mediastinitis & 5.6 & 33.3 & 0.006 \\
\hline Table 8. Analysis of Complications of DNSI in the Clinical \\
Presentation \\
\hline \multicolumn{4}{|c}{} \\
\hline
\end{tabular}

\section{DISCUSSION}

Our results show interesting similarities and differences with the literature. The mean age that was affected most by infection in the literature varied from 36 to 57 years, 2,3,5-10 which was similar to our findings. The disease was twice more frequent in males, as many authors have reported.5-8,11 Smoking and drinking alcohol were the most commonly associated social habits. The most commonly found systemic diseases were diabetes and systemic arterial hypertension. The literature has reported a $16 \%$ to $20 \%$ incidence of diabetes. ${ }^{8}$ Systemic arterial hypertension, which may be associated with heart and lung diseases is not given importance. These factors may have an influence on the morbidity and mortality of DNI. The HIV has been found in $7 \%$ of cases 6 in the literature. In our study, however, it was found in only 3 patients (3.75\%).

The clinical picture of infection with oedema of the neck, odynophagia, fever, trismus, a poor health status associated or not with a primary condition is similar to that found in the literature.8,12 In our study, the presence of tachycardia, toxaemia, signs of tissue necrosis and respiratory failure were associated with a poor prognosis in these patients.

DNI originate from a variety of sites in the head and neck. These include the teeth, the salivary glands, the lymphoid tissues and the tonsils. The teeth are the most common primary site (31\% to $80 \%)$ followed by the tonsils $(1.5 \%$ to $3.4 \%)^{1,5-8,10-18}$; the latter is more frequent in children. ${ }^{19-22}$ Odontogenic conditions were the most common cause in our series $(27.5 \%)$ followed by tonsillar disease $(22.5 \%)$. The cause remained unknown in 20 patients (25\%), 
notwithstanding a detailed clinical history, physical examination and radiological studies. The oropharynx was probably the site of origin in these cases. Other studies have also shown a significant proportion (around 16\% to 39\%) of DNI of unknown origin. 10-13

About two-thirds of the cultures of secretions were polymicrobial. ${ }^{6}$ The most commonly isolated organisms are mostly part of the normal oropharyngeal flora. ${ }^{7}$ In our series, Staphylococcus aureus was the most commonly isolated bacteria (37.5\%) followed by Group G Streptococci (25\%). Authors have presented a wide variation of bacteria associated with mixed infection. The most common bacteria that have been encountered have been Streptococci viridans, Staphylococcus epidermidis and Staphylococcus aureus. ${ }^{4,6,8}$ There was no bacterial growth in 13 cultures $(16.25 \%)$. This is a low rate compared to that of authors (which has ranged from $27 \%$ to $40 \%)_{.8,11}$ This is probably due to the indiscriminate use of antibiotics prior to hospital admittance and the high doses of endovenous antibiotics before surgery. ${ }^{12}$

The most commonly involved areas in our study were the submandibular and parapharyngeal spaces. Moncada et al ${ }^{14}$ have established the dissemination routes for odontogenic neck infections. These authors have demonstrated the anatomical relations between the submandibular and parapharyngeal spaces, and have explained the pathophysiology of Ludwig's angina. Involvement of the parapharyngeal space, the association between the parapharynx + mediastinum + pleura or the retropharynx + mediastinum were associated with a poor prognosis.

Since the 1970s, computed tomography has evidently helped improve the diagnosis of DNI.15,16 Tomography of the neck and thorax establish the extension of infection and make it possible to precisely plan the treatment.

All of the patients in whom the above-mentioned spaces involved were treated surgically, except for 2 patients that had a well-defined peritonsillar infection in the suprahyoid area of the neck. These two patients had been using nonprescribed antibiotics for a prolonged period and had no signs of significant toxaemia. They progressed well with high doses of intravenous antibiotics, and there was spontaneous intraoral drainage.

Special attention should be given to airway management when patients present trismus or signs of upper airway obstruction, particularly in Ludwig's angina, in which there is oedema of the oral floor due to bilateral submandibular space infection. Parhiscar et $\mathrm{al}^{10}$ analysed 210 patients with neck abscesses and reported a need for tracheostomy under anaesthesia in $44 \%$ cases, which demonstrates the severity of this condition. We agree that adequate management of airways with intubation using flexible fibroscopy and/ or a tracheostomy in cases of significant trismus and oedema of the tongue is a priority in the initial approach to DNI.17,18

Our complication rate was $12.5 \%$, which is similar to findings in the literature. These have ranged from $12.85 \%$ to $25.5 \%, 10,13$ mostly associated with mortality. DNI are severe conditions that may rapidly progress to necrotising fasciitis; descending mediastinitis, in which the mortality rate is $40 \%$ to $50 \%$, may or may not complicate the condition, due to its rapid progression to septic shock. The mortality rate in our series was $11.25 \%(n=9) ; 7$ patients died due to infection and 2 patients died due to non-infectious causes.
Mediastinitis and septic shock were related to a poor prognosis of the infection.

Prompt recognition and treatment of DNI are essential for an improved prognosis. Thus, key elements for improved results are the identification of morbid factors, signs and symptoms and computed tomography.

\section{CONCLUSION}

The Current Study enabled us to conclude that-

1. Odontogenic and tonsillar causes are the most common;

2. The submandibular and the parapharyngeal areas are the main microorganisms involved in this condition;

3. Staphylococcus aureus and Group G Streptococci are the main microorganisms involved in this condition;

4. A priority in the treatment of DNSI should be an adequate management of airways, if surgery is indicated no muscle relaxants should be given;

5. Surgical drainage is the standard treatment of DNSI;

6. Computed tomography is the test of choice for the diagnosis of DNSI;

7. DNSI have high morbidity and mortality rates, particularly when associated with septic shock and mediastinitis.

\section{REFERENCES}

[1] Wang LF, Kuo WR, Tsai SM, et al. Characterizations of life-threatening deep cervical space infections: a review of one hundred ninety-six cases. Am J Otolaryngol 2003;24(2):111-7.

[2] Durazzo M, Pinto F, Loures M, et al. Deep neck spaces and their significance in cervical infections. Rev Ass Med Brasil 1997;43(2):119-26.

[3] Wong TY. A nationwide survey of deaths from oral and maxillofacial infections: the Taiwanese experience. J Oral Maxillofac Surg 1999;57(11):1297-9.

[4] Weed H, Forest L. Deep neck infection. J Otolaryngol Head and Neck Surg 1998;3:2515-24.

[5] Ungkanont K, Yellon RF, Weissman JL, et al. Head and Neck space infections in infant and children. Otolaryngol Head Neck Surg 1995;112(3):375-82.

[6] Huang TT, Liu TC, Chen PR, et al. Deep neck infection: analysis of 185 cases. Head \& Neck 2004;26(10):85460 .

[7] Hasegawa J, Hidaka H, Tateda M, et al. An analysis of clinical risk factors of deep neck infection. Auris Nasus Larynx 2011;38(1):101-7.

[8] Flynn TR. Anatomy of oral and maxillofacial infections. In: Topacian RG, Goldberg MH, Hupp JR. eds. Oral and Maxillofacial Infections. $4^{\text {th }}$ edn. St. Louis: WB Saunders 2002:188-206.

[9] Mayor PG, Martinez-San MJ, Martinez-Vidal A. Is conservative treatment of deep neck space infections appropriate? J Head and Neck 2001;23(2):126-33.

[10] Parhiscar A, Har-El G. Deep neck abscess: a retrospective review of 210 cases. Ann Oto Rhinol Laryngol 2001;110(11):1051-4.

[11] Sakaguchi M, Sato S, Ishiyama T, et al. Characterization and management of deep neck infections. Int J Oral Max Surg 1997;26(2):131-4.

[12] Sethi DS, Stanley RE. Deep neck abscesses--changing trends. J laryngol Otol 1994;108(2):138-43. 


\section{Jemds.com}

[13] Tom MB, Rice DH. Presentation and management of neck abscess: a retrospective analysis. Laryngoscope 1988;98(8 Pt 1):877-80.

[14] Moncada R, Warpeha R, Pickleman J, et al. Mediastinitis from odontogenic and deep cervical infection. Anatomic pathways of propagation. Chest 1978;73(4):497-500.

[15] Endicott JN, Nelson RJ, Saraceno CA. Diagnosis and management decisions in infections of the deep fascial spaces of the head and neck utilizing computerized tomography. Laryngoscope 1982;92(6 Pt 1):630-3.

\section{Original Research Article}

[16] Munoz A, Castillo M, Melchor MA, Gutierrez R. Acute neck infections: prospective comparison between CT and MRI in 47 patients. J Comp Ass Tomogr 2001;25(5):733-41.

[17] Heindel DJ. Deep neck abscesses in adults: management of a difficult airway. Anesth Analg 1987;66(8):774-6.

[18] Shockley WW. Ludwig angina: a review of current airway management. Arch Otolaryngol Head and Neck Surg 1999;125(5):600. 